\title{
Effects of Resistant Starch Intake in Humans
}

\author{
S Katherine Sweatt, MAEd ${ }^{1 *}$, Gordon Fisher, $\mathrm{PhD}^{2}$ and Barbara A Gower, $\mathrm{PhD}^{1}$ \\ ${ }^{1}$ University of Alabama at Birmingham, Department of Nutrition Sciences \\ ${ }^{2}$ University of Alabama at Birmingham, Department of Human Studies
}

\begin{abstract}
*Corresponding author: S. Katherine Sweatt MAEd, Department of Nutrition Sciences, University of Alabama at Birmingham, 1675 University Boulevard, Webb Building 427, Birmingham, AL 35429, USA; Tel: 205-975-9629; Fax: 205-934-7050; E mail: sksweatt@ uab.edu
\end{abstract}

Article Type: Review, Submission Date: 05 June 2015, Accepted Date: 12 December 2015, Published Date: 18 January 2016.

Citation: S Katherine Sweatt MAEd, Gordon Fisher PhD and Barbara A Gower PhD (2016) Effects of Resistant Starch Intake in Humans. F Nutr Reprt 1(2): 19-26. doi: https://doi.org/10.24218/fnr.2015.09.

Copyright: (c) 2016 S Katherine Sweatt, et al. This is an open-access article distributed under the terms of the Creative Commons Attribution License, which permits unrestricted use, distribution, and reproduction in any medium, provided the original author and source are credited.

\section{Abstract}

Due to the rise in obesity and obesity-related conditions, there is growing commercial and public interest in foods and food components that promote health and lower risk of chronic metabolic diseases. Resistant starch (RS) is a non-viscous fermentable fiber that has beneficial metabolic effects on glucose tolerance, insulin sensitivity, and colon health in humans. While the mechanism behind the effects of RS are unclear, the benefits are thought to result from fermentation of RS in the large bowel by colonic bacteria resulting in a more favorable gut microbial composition and increased concentration of short-chain fatty acids (SCFAs). Evidence indicates that RS may result in increased colonic bacterial species Ruminococcus bromii (R. bromii), and in phylum level changes in Bacteriodetes and Fermicutes. The increase in SCFAs has been shown to potentially play a role in lowering gut $\mathrm{pH}$ to improve health, contribute to appetite control and reduced adipose tissue lipolysis; and reduce postprandial serum oxidative stress. Additionally, evidence indicates RS aids in treatment of diarrheal disease by interacting with both the human to increase SCFA concentration, water retention, and fecal weight and to interact with the disease-causing agent such that the insult to the human lumen cells is reduced. Therefore, RS may be a potent dietary therapy for individuals at risk for conditions including metabolic syndrome, type-2 diabetes, colorectal cancer, and diarrheal diseases. The effects of type, dose, and duration of RS intake and subsequent impact on health are important areas of further research.

Keywords: Resistant starch, Short chain fatty acids, Fiber, Gut, Microbiota, Firmicutes, Bacteroides, Colonocytes, Cancer, Inflammatory bowel disease, Oxidative stress

\section{Introduction}

A typical Western diet is characterized by low intake of fruits and vegetables and high intake of refined foods rich in saturated fats and simple carbohydrates. This dietary pattern is a chief contributor to obesity and related diseases [1]. Obesity is associated with an array of metabolic and cardiovascular conditions including type- 2 diabetes, heart disease, and some cancers [2]. Because of the rise in obesity and obesity-related conditions, there is growing commercial and public interest in foods and food components that promote health and lower risk of chronic metabolic diseases.

Dietary fiber is derived from plants and is composed of complex carbohydrates that are resistant to digestion and absorption in the small intestine because mammals lack the enzymes necessary for hydrolysis. When the fiber compounds reach the colon, they undergo complete or partial fermentation by the bacteria that inhabit the colon $[3,4]$. Evidence shows that dietary fibers are linked to management of digestion and bowel health, and reduced cholesterol and glucose levels, among others. It is recommended that $25-38 \mathrm{~g}$ of dietary fiber are consumed per day, however many individuals do not meet these recommendations, particularly in westernized societies [5]. In agrarian countries, where dietary fiber consumption constitutes more than $50 \%$ of daily energy intake, reports indicate lower incidence of metabolic and cardiovascular diseases compared to westernized societies [6]. In addition, epidemiological studies have shown an inverse relationship with diets high in fiber and heart disease as well as T2D [7-9]. Therefore, increasing fiber intake may improve health and decrease risk of cardiometabolic disease.

Resistant starch (RS) is a non-viscous fermentable fiber that is easily fortified into food products [10] and has generally been shown to have beneficial metabolic effects on glucose tolerance and insulin sensitivity, endothelial function, and colon health $[11,12]$. Refer to $[10,13]$ for comprehensive reviews of the effect of RS on insulin sensitivity. While the mechanism behind the effects of RS are unclear, there is emerging interest in RS as an important dietary component to improve colon health and metabolic health. Benefits of RS may be largely due to fermentation of RS in the large bowel by colonic bacteria. The aim of the present article is to review the scientific evidence for the potential benefits of RS on human metabolic health through fermentation in the gut. 


\section{Dietary Starch}

Digestion of starch begins in the mouth where food is broken into smaller pieces by chewing. Starch is broken down into oligosaccharides by a-amylase, an enzyme in saliva. The bolus is swallowed and transported to the stomach and then to the small intestine. Starch has different rates of digestion depending on the structural properties and the processes applied to the foods containing starch. In nature, starch exists as granules, which contain two major polysaccharides: amylose and amylopectin. Amylose is a predominantly linear while amylopectin is a highly branched polymer and one of the largest known natural occurring polymers. The branched-chain structure of amylopectin is more open and accessible to breakdown by amylase, therefore it is rapidly digested and absorbed. In contrast, amylose is a tightly packed molecule and more resistant to breakdown (Figure 1) [14]. Consequently, starch is classified as rapidly digestible (RDS),

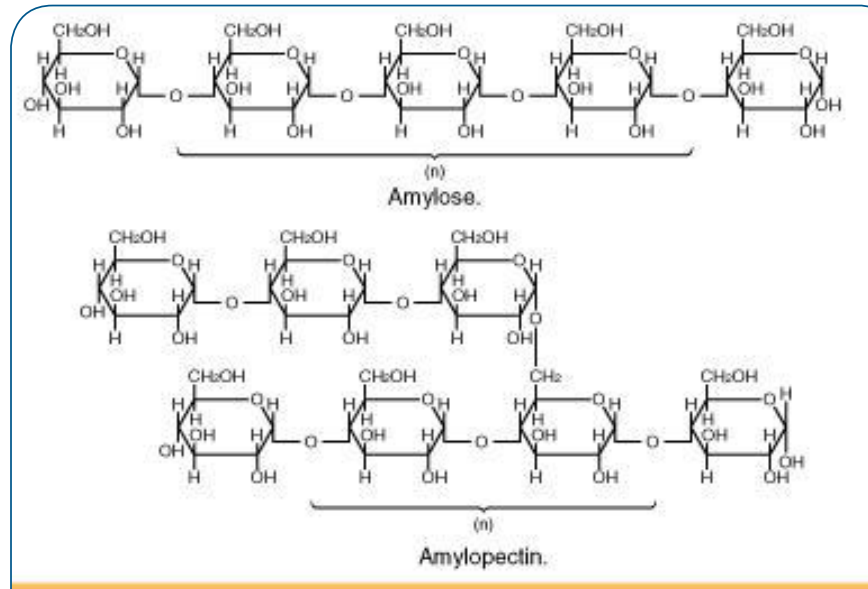

Figure 1: (a) Illustration of the linear structure of amylose and (b) branched structure of amylopectin

slowly digestible (SDS), and RS according to the susceptibility of starch to digestion by pancreatic amylase [15]. Digestion depends on properties such as granular structure of the starch, amylose to amylopectin ratio, and size of the starch particles consumed. RS is defined as the sum of starch and products of starch degradation not absorbed in the small intestine [16].

Four types of RS have been identified which vary by botanical source and processing (Table 1) [17]. RS1 is trapped within whole grains or seeds and is physically inaccessible to digestive enzymes. RS2 refers to the starch granules as in potato, banana, and high amylose maize. The conformation and structure of the starch granule cause the starch to be resistant to digestion. RS3 is retrograded starch and usually acquired after processing commonly after cooking and cooling. Novelose is a marketed form of RS3. RS4 is chemically modified starch. Fibersym is the most common marketed RS4. RS1 and RS2 are both naturally occurring; however RS2 can be genetically engineered. RS2 is marketed as Hi-Maize, which is one of the richest natural sources of RS. High-amylose maize starch (HAM), contains $\geq 50 \%$ amylose and has been investigated most extensively in humans because it is easily incorporated into foods without altering processing properties (Figure 2) [17].

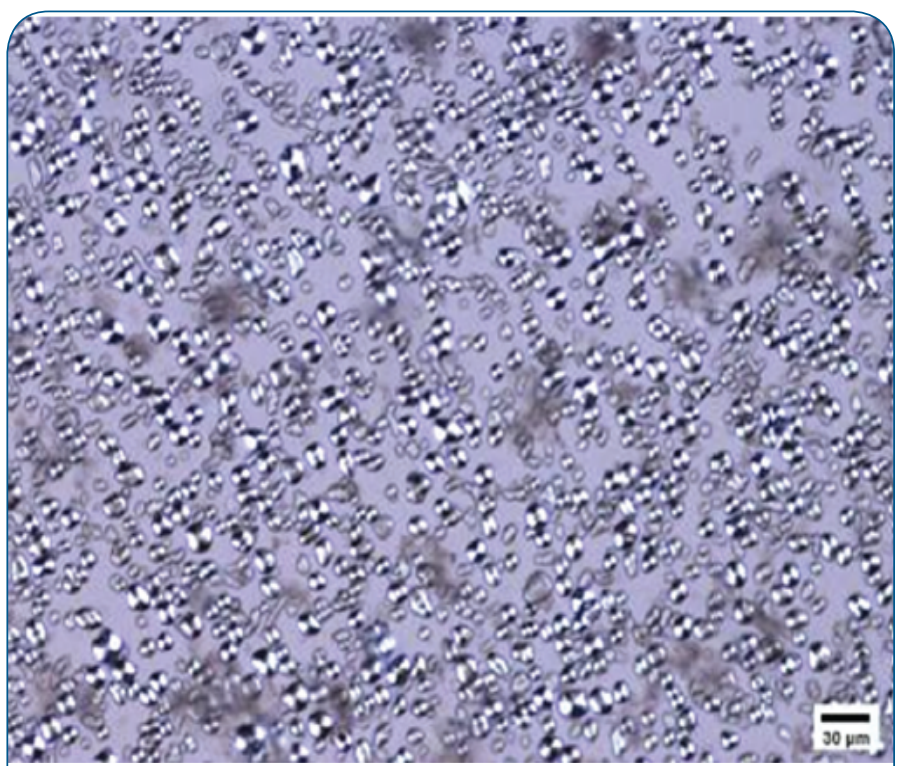

Figure 2: Granular structure of HAM-RS2-enriched yogurt imaged

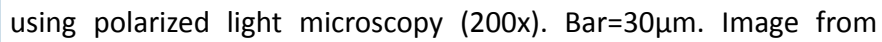
Aryana et al. F1000Research 2015, 4:139

\section{Resistant Starch and Microbiota}

The gastrointestinal (GI) tract is inhabited by about 100 trillion bacteria collectively referred to as the gut microbiota. The microbiota is critical for maintaining immune function, GI health, and normal digestion of nutrients. [18]. Obesity, malnutrition, inflammatory bowel disease, neurological disorders, gutderived infections, and some cancers have been associated with dysfunction in the gut microbiota [19]. Healthy adults generally share the same core microbiota dominated by bacterial species from the Firmicutes and Bacteroides families [20]. Bacteroides are generally thought to benefit the host by fighting pathogens in the gut while Firmicutes are involved in energy absorption [21]. Recent evidence suggests that the distribution of certain dominant bacterial species varies among individuals due to factors such as weight status and diet $[22,23]$. Diet composition, specifically intake of RS, has been found to have a considerable

Table 1: Types of starch and digestion rate ${ }^{[16,88]}$

\begin{tabular}{|l|l|l|}
\hline Type of Starch & Example & Digestion \\
\hline Rapidly digestible & Cooked starchy foods & Rapid \\
\hline Slowly digestible & Raw cereals & Slowly but complete \\
\hline RS1: physically inaccessible & Partially milled grains and seeds & Resistant \\
\hline RS2: resistant granules & Raw potato, green banana, high amylose maize & Resistant \\
\hline RS3: retrograded starch & Cooked and cooled (e.g. pasta) & Resistant \\
\hline RS4: chemically modified & Starch ethers and esters & Resistant \\
\hline
\end{tabular}

RS: Resistant Starch 
impact on specific groups of bacteria in humans that may affect health [21].

There is evidence indicating that RS may promote growth of various species of bacteria that inhabit the colon, as RS is a fuel source metabolized by colonic bacteria. Changes in bacteria composition occur quickly, within only 3 days of RS intake then returned to previous levels once RS intake is ceased [21]. Alterations have been observed in bacterial species composition with RS2, RS3, and RS4 supplementation in humans, however results vary with dose and type of RS. RS2 and RS3 supplementation has been shown to increase the bacteria species Ruminococcus bromii (R. bromii), belonging to the Firmicutes family, indicating the ability of these bacteria to colonize and to utilize RS as an energy source. [21,24]. Ruminococci species facilitate fermentation of carbohydrates in the colon. $R$. bromii specifically, appears to adhere to HAM starch and play an important role in fermentation of RS $[25,26]$. RS4 compared to RS2 supplementation in healthy humans increased Bacteriodetes and decreased Firmicutes. RS2, however was associated with increased R. bromii. Another study found $10 \mathrm{~g}$ /day of RS3 to increase bifidobacterium, a species in the Actinobacterial class, in healthy humans [27]. Some strains of bifidobacterium are thought to have a range of health benefits in the colon including regulating microbial homeostasis in the intestine, suppressing pathogens and harmful bacteria, and converting of dietary compounds into bioactive molecules [28]. Taken together, evidence suggests that RS may provide fuel through increasing bacteria associated with carbohydrate fermentation as well as increasing bacteria beneficial to homeostasis and protection of the colon.

Whether these changes in bacterial composition that have been observed with various type of RS intake result in any health benefits has not been established. Further investigation into the effects of different types of RS intake on gut health is an important area of future research.

\section{Short Chain Fatty Acids}

While RS may improve microbial composition, the beneficial effects of RS are thought to be due to increased production of short-chain fatty acids (SCFAs) which are by-products of microbial fermentation of RS in the gut [29]. SCFAs are one of the most essential microbial products affecting a number of physiological processes such as energy utilization, host-microbe signaling, production of secondary bile acids, control of colonic $\mathrm{pH}$, and gut motility. In addition, SCFAs play a role in epithelial cell proliferation and are associated with reduced diet-induced DNA damage and decreased precancerous lesions [30]. SCFAs are metabolized rapidly by the colon epithelial cells, referred to a colonocytes, which line the villi of the colon. They serve as the major respiratory fuel for the colon supplying $60-70 \%$ of the energy needs of isolated colonocytes.

The majority of SCFAs are taken up by the colon. In fact, less than $5 \%$ of SCFAs appear in feces. SCFA uptake into the portal circulation influences the upper gut musculature to decrease gastric tone thereby resulting in expansion of volume after ingestion of RS. This action is important for the function of the GI system. SCFAs have a trophic effect in the colon, stimulating growth of colorectal and ileal mucosal cells [31]. SCFAs are sensed by $G$ protein-coupled receptors, GPR41 and GPR43 which are expressed in the distal small intestine, colon, and in adipocytes [32,33].

The most common SCFAs are butyrate, acetate, and propionate, which make up approximately $80 \%$ of SCFAs [34]. Butyrate is known to be most beneficial for colon health because it is the preferred energy source for bacteria and colonocytes. It promotes normal cell differentiation and proliferation, therefore may play a role in the prevention of cancerous lesions and other colon disorders Absorbed propionate and acetate are transported to hepatocytes and consumed for gluconeogenesis [33]. Though speculative, propionate may be protective against cardiovascular disease by potentially decreasing the absorption of dietary cholesterol. This would be evident by altering LDL-cholesterol and $\mathrm{C}$-reactive protein (CRP) levels, which are biomarkers of cardiovascular disease [35]. Acetate has been shown in vivo to suppress adipose tissue lipolysis causing reduced non-esterfied fatty acid (NEFA) and glycerol levels [36-38,39]. A deficiency of SCFAs in the intestine, particularly butyrate, is related to inflammation in the colon and ulcerative colitis [40].

\section{Gut pH}

SCFA are relatively weak acids. Raising the concentration of SCFA through fermentation in the colon results in decreased $\mathrm{pH}$. Decreasing colon $\mathrm{pH}$ reduces the colonic bile acid production and the solubility of bile acids, which is thought to reduce the cell-damaging properties of fecal water (or components of feces in contact with colonic mucosal cells) and protect against colon cancer. It is thought that increased SCFA production due to RS intake decreases cytotoxic bile acid production in the colon thereby reducing risk of colon cancer [41-43].

The effects of RS on large bowel $\mathrm{pH}$ in humans is limited to fecal values. Noakes et al. observed an increase in butyrate and a significantly decreased $\mathrm{pH}$ in fecal matter of human subjects fed HAM RS2 compared to the control diet [31]. There was also an increase in stool frequency with the HAM RS2 diet. Another study found that two weeks of $28 \mathrm{~g} /$ day RS2 intake increased SCFA excretion, decreased colonic bile acid concentration and cytotoxicity of fecal water, and reduced colonic mucosal proliferation in rectal biopsies [44]. In contrast, $32 \mathrm{~g} / \mathrm{d}$ of either RS2 or RS3 intake for 1 week resulted in increased breath hydrogen (an indicator of increased colonic fermentation) and stool weight, however, there was no change in $\mathrm{pH}$, SCFA concentration, bile acid, or cytotoxicity of fecal water [42]. Duration of RS intake may be a factor causing varying results between studies. While data suggest $\mathrm{RS}$ intake may lower gut $\mathrm{pH}$, it is unclear whether gut health is improved.

\section{Appetite Control}

There may be a role for RS in appetite control. The increased time needed to chew foods containing high fiber and RS may increase satiety as chewing stimulates saliva and gastric acid production. This, in turn, increases gastric distention and feelings of fullness [35]. Evidence also suggests that RS consumption may decrease the rate of glucose absorption in the small intestine, thereby reducing the insulin response and increasing satiation [45]. de Roos et al. observed significantly lower appetite scores with 4 weeks of $30 \mathrm{~g} /$ day HAM RS2 consumption compared to retrograded RS3 in healthy men [46]. However, participants felt 
Citation: S Katherine Sweatt MAEd, Gordon Fisher PhD and Barbara A Gower PhD (2016) Effects of Resistant Starch Intake in Humans. F Nutr Reprt 1(2): 19-26. doi: https://doi.org/10.24218/fnr.2015.09.

less full while consuming the HAM RS2. HAM RS2 consumption in an acute dose of $48 \mathrm{~g}$ was shown to reduced energy intake for the next 24 hours compared to placebo, however there was no effect of RS consumption on appetite scores [47]. These findings suggest RS2 may have beneficial implications in appetite control and weight management. Further studies are needed to determine appropriate dosage of RS and the effect of RS on appetite and food intake in overweight and obese individuals.

Evidence suggests that SCFA may have a role in satiety signaling, providing a potential mechanism underlying the effect of RS consumption and appetite control. SCFAs activate the L-cells to secrete hormones peptide YY (PYY) and glucagon-like peptide (GLP)-1 [48]. The release of these hormones in response to food consumption activates neural pathways that lead to altered metabolic rate, regulation of gut motility, and reduced appetite [49]. SCFAs act as ligands for G-protein-coupled receptors (GPRs) GPR43 and free fatty acid receptors 2 and 3 (FFAR2, FFAR3). These receptors are activated by increased SCFAs in circulation. GPR43, FFAR2, and FFAR3 are colocalized within L-cells in the human large intestine which has led to the suggestion that activation of these receptors by SCFA ligands may facilitate PYY and GLP-1 release. Subsequently, increasing RS in the diet may increase these gut hormones, thus leading to reduced energy intake and long-term weight loss. To achieve this effect, however, likely requires high consumption of RS, which may lead to side effects such as bloating, cramping, flatulence, and soft stool [49]. Further investigation is necessary to determine the effects of RS on satiety hormones in humans.

\section{Adipose Tissue Lipolysis}

It is now clear that RS, generally HAM RS2, consumption improves insulin sensitivity [12,50-52]. This may be a secondary result of alterations in fatty acid flux associated with RS fermentation and SCFA production. Fatty acid metabolism is a critical factor in determining tissue insulin sensitivity. Abnormalities in fatty acid storage and lipolysis cause increased fatty acid flux on tissues such as liver and skeletal muscle [51]. This is a central event in the development of insulin resistance. SCFA are absorbed into the blood stream where they are metabolized by muscle and adipose tissue. Robertson et al. found increased systemic concentrations of acetate and propionate after 4 weeks of HAM RS2 supplementation compared to placebo in ten individuals [51]. They also found a significant increase in SCFA uptake across both skeletal muscle and adipose tissue and lower postprandial nonesterfied fatty acids (NEFA) after a meal tolerance test with 4 weeks of RS supplementation compared to placebo. In a later study, Robertson et al. found increased expression of genes involved in lipid uptake and mobilization including lipoprotein lipase (LPL), hormone-sensitive lipase (HSL), and adipose triglyceride lipase (ATGL) [10]. Increased expression of these lipases is beneficial because HSL is the primary lipase for lipolysis and AGTL has been shown to mediate triglycerides during basal lipolysis [53,54]. Expression of these genes is typically reduced in obesity and type- 2 diabetes, signifying failure of adipose tissue to differentiate. In addition, obesity and ty[e 2 diabetes are characterized by altered regulation of FFA flux. Increased expression of these genes implies increased capacity for fat storage and proper adipose tissue function, and ultimately beneficial to health.

Increased circulating SCFAs from fermentation of RS inhibit adipose tissue lipolysis though interaction with FFAR2 and FFAR3 thereby reducing plasma NEFA. Acetate and propionate are highly bioactive and have been shown to dosedependently inhibit adipose tissue lipolysis in mice infused with sodium acetate [55]. Further, SCFAs influence adipose tissue adipogenesis through interaction with FFAR2, a mediator of adipocyte development and differentiation, which results in smaller adipocyte size and lower secretion of pro-inflammatory cytokines. These observations may have important implications in obesity and type- 2 diabetes which are characterized by large adipocytes and systemic inflammation. There is mounting evidence to suggest that RS intake may influence fat metabolism and lead to improved insulin sensitivity.

\section{RS and Oxidative Stress}

There are few human studies indicating a role for RS in oxidative stress. Kwak et al. investigated the effects of RS on postprandial oxidative stress in prediabetic individuals [11]. Consumption of a high-fat and/or carbohydrate meal results in postprandial oxidative stress (oxidative stress caused by the metabolism of a consumed meal), particularly a meal high in saturated fat [56-58]. Over time, poor diet quality leads to increased oxidative stress, which has been associated with increased risk of atherosclerosis and related disorders [57]. Their findings indicated that consumption of rice containing HAMRS2 for 4 weeks resulted in improved endothelial function, reduced postprandial glucose, and reduce oxidative stress in patients with impaired fasting glucose or impaired glucose tolerance [11]. Endothelial dysfunction is an early indicator of vascular damage and cardiovascular disease [59]. These findings suggest RS may have a beneficial effect in the postprandial period through reducing oxidative stress and subsequent progression of CVD.

\section{Cancer}

Colorectal cancer (CRC) was the third most common cancer in the United States in 2010 and has the second highest mortality rate [60]. CRC develops when damage to colonocytes, cells which line the large intestine, occurs giving these cells characteristics allowing increased proliferation, resistance to death, and eventually, potential for metastasis [61]. Evidence suggests that diet may play a role in promoting and/or protecting against colonic carcinogenesis. Epidemiological data indicate reduced risk in populations with high vegetable consumption [62]. It is thought that this may be due to the complex carbohydrate content, such as dietary fiber. RS has been proposed to be chemoprotective in humans through promoting growth of beneficial bacteria in the intestine, increasing the short-chain fatty acid butyrate concentration, and having a suppressing effect on conversion of primary to secondary bile acids in the large intestine $[63,64]$. A gold standard biomarker for colorectal cancer has not been established, therefore, concluding whether RS has an effect on cancer risk is difficult to determine.

Few studies have investigated the effect of RS on CRC in humans and thus far have yielded inconsistent results. One study reported a possible detrimental effect such that potential for oxidative stress and subsequent DNA damage was increased in 12 healthy 
participants when fed $60 \mathrm{~g} /$ day of highly resistant HAM RS, Hylon VII [65]. Two years of $30 \mathrm{~g} /$ day of RS2 showed no effect in the development of adenomas or colorectal cancer risk in individuals with Lynch syndrome [66]. Most studies in humans have found no association with RS and cancerous cell proliferation [65,67-70], however one study found a decrease in cells undergoing mitosis in the upper portion of the colon after RS supplementation compared to placebo in colorectal cancer patients [68]. There was no effect of RS on tumor cell proliferation, however there were also beneficial changes in expression of key cell cycle regulatory genes and the authors concluded that RS may have a favorable effect on colorectal cancer [68]. Malcomson et al. proposed RS may be protective by modulating the WNT signaling pathway through increased butyrate concentration [71]. There are three WNT pathways characterized by signal transduction pathways made of proteins that pass signals from the outside to the inside of a cell through cell surface receptors. WNT plays an important role in regulating large bowel cell proliferation and butyrate modulates this pathway in a beneficial manner. Abnormal WNT signaling has been shown in CRC; therefore increased butyrate circulation with RS intake may reduce CRC risk by way of the WNT signaling pathway. Although evidence that RS is protective against CRC is inconsistent and speculative, the potential for RS to have an effect on CRC merits further research.

In vitro studies have shown cancer-protective effects of RS in the colon due to increased SCFAs, namely butyrate, and their role in inhibiting cell proliferation and inducing apoptosis [72]. Wacker et al. studied the effects of HAMRS2 consumption on oxidative stress and DNA damage in colon mucosal cells of healthy individuals [65]. Their findings indicated that the HAMRS2 diet resulted in increased oxidative stress and DNA adducts compared to a control diet. These findings are thought to accelerate carcinogenesis, therefore RS may have a detrimental effect on mucosal cells in the colon. This is the first study investigating the relationship between RS and oxidative stress in colonic mucosal cells in humans, thus further research is needed to delineate the effects of RS and SCFAs in the colon.

\section{Bowel inflammatory and diarrheal diseases}

Inflammatory bowel diseases (IBD), such as Crohn's disease and ulcerative colitis are, are characterized by abdominal pain, diarrhea, rectal bleeding, intestinal inflammation, and ulceration [73]. Diets high in fiber, fruits, and vegetables are thought to protect against inflammation and CRC [74]. Few studies have investigated the effects of RS on IBD in humans, however it is hypothesized that RS can potentially increase fecal bulk, decrease $\mathrm{pH}$, reduce constipation, and improve microbial composition, thereby reducing the incidence and risk of IBD manifestations. However, RS intake may also exacerbate symptoms, as bloating and increased gas has been shown at higher doses [75]. See Higgins et al [76] for a review of RS on IBD. The main beneficial effect of RS in IBD is thought to be due to increased circulating SCFAs, particularly butyrate [77]. Studies have shown butyrate to have an anti-inflammatory effect on the NF-kappaB pathway when activated by proinflammatory cytokines. Additionally, there is evidence that SCFAs have anti-tumor effects by increasing susceptibility of colon cancer cells to cell death [78]. This is achieved through regulation of cell cycle proteins to induce apoptosis. Refer to Andoh et al [79] for a review of the effects of
SCFAs on inflammatory pathways in the colon.

Diarrheal diseases, such as cholera, are one of the main causes of infant and child death in developing countries affecting more than 3 million children every year [80]. Maintaining fluid balance is crucial to survival of diarrheal diseases. Addition of RS to oral rehydration therapies was suggested due to the ion absorption properties of increased SCFA. Patients with cholera fed HAMRS2 experienced shortened duration of diarrhea and reduced fecal fluid loss [81]. This is thought to be due to increased SCFAs, particularly butyrate, in the colon which stimulate sodium and water absorption by the colon [82-85]. Gancz et al. discovered that HAMRS2 interacts with pathogenic serogroup $V$. choleraI such that $V$. cholera adheres to HAMRS2 [86]. Therefore, HAMRS2 may function by two possible to improve cholera and other diarrheal diseases: 1) interaction with the human body (i.e. increased SCFAs, fecal bulking, and slower transit time) or 2) interaction with the diarrhea-causing agent. In a follow-up study, it was determined that $V$. choleraI adheres to starch granules in the colon providing an alternative energy source to human lumen and reducing colonization and subsequent infection [87].

\section{Conclusions}

Many studies have demonstrated that RS may have beneficial effects in human health that are likely due to fermentation in the gut. Some data indicates that RS may improve health through favorable increases in gut microbial composition. While RS has been shown to change microbial composition, investigation into how different types of RS effect microbial composition and health is an important area for future research. Much evidence points towards the beneficial effects of RS resulting from increased SCFA concentration due to RS fermentation in the gut. Additionally, several human studies have also demonstrated improved insulin sensitivity [50,52]. Studies also indicate a possible role for RS in reducing CRC risk, improving fat metabolism, appetite control, and postprandial oxidative stress. Additionally, RS appears to have a clear impact on certain diarrheal diseases, specifically cholera, through interaction with the disease-causing agent and/or benefits of increased SCFAs. While the underlying mechanisms of RS remain unclear, RS may be a potent dietary therapy for individuals at risk for metabolic syndrome, type-2 diabetes, colitis and colon cancer, diarrheal diseases, and obesity. Further human research into the optimal dose and duration of RS intake as well as the target population for its use is warranted. The long-term adaptive effects of RS in microbiota and colonic fermentation are unknown. Further investigation into longterm exposure to RS, particularly in the setting of obesity and/ or diabetes, will reveal the effect of long-term RS intake as a treatment or pharmacological therapy.

\section{References}

1. Hu FB, van Dam RM, Liu S. Diet and risk of Type II diabetes: the role of types of fat and carbohydrate. Diabetologia. 2001; 44(7):80517.

2. de Vries J. The obesity epidemic: medical and ethical considerations. Sci Eng Ethics. 2007; 13(1):55-67.

3. Bartlomiej S, Justyna RK, Ewa N. Bioactive compounds in cereal grains - occurrence, structure, technological significance and nutritional benefits - a review. Food Sci Technol Int. 2012; 18(6):55968. doi: 10.1177/1082013211433079. 
Citation: S Katherine Sweatt MAEd, Gordon Fisher PhD and Barbara A Gower PhD (2016) Effects of Resistant Starch Intake in Humans. F Nutr Reprt 1(2): 19-26. doi: https://doi.org/10.24218/fnr.2015.09.

4. Overby NC, Sonestedt E, Laaksonen DE, Birgisdottir BE. Dietary fiber and the glycemic index: a background paper for the Nordic Nutrition Recommendations 2012. Food Nutr Res. 2013; 57. doi: 10.3402/fnr.v57i0.20709.

5. Mobley AR, Slavin JL, Hornick BA. The Future of Grain Foods Recommendations in Dietary Guidance. J Nutr. 2013; 143(9):1527S1532S. doi: 10.3945/jn.113.175737.

6. Morris JN, Marr JW, Clayton DG. Diet and heart: a postscript. $\mathrm{Br}$ Med J. 1977; 2(6098):1307-14.

7. Anderson JW. Dietary fibre, complex carbohydrate and coronary artery disease. Can J Cardiol. 1995; 11(Suppl G):55G-62G.

8. Liu S, Stampfer MJ, Hu FB, Giovannucci E, Rimm E, Manson JE, et al. Whole-grain consumption and risk of coronary heart disease: results from the Nurses' Health Study. Am J Clin Nutr. 1999; 70(3):412-9.

9. de Munter JS, Hu FB, Spiegelman D, Franz M, van Dam RM. Whole grain, bran, and germ intake and risk of type 2 diabetes: a prospective cohort study and systematic review. PLoS Med. 2007; 4(8):e261.

10. Robertson MD. Dietary-resistant starch and glucose metabolism. Curr Opin Clin Nutr Metab Care. 2012; 15(4):362-7. doi: 10.1097/ MCO.0b013e3283536931.

11. Kwak JH, Paik JK, Kim HI, Kim OY, Shin DY, Kim HJ, et al. Dietary treatment with rice containing resistant starch improves markers of endothelial function with reduction of postprandial blood glucose and oxidative stress in patients with prediabetes or newly diagnosed type 2 diabetes. Atherosclerosis. 2012; 224(2):457-64. doi: 10.1016/j.atherosclerosis.2012.08.003.

12. Robertson MD, CurrieJM, Morgan LM, JewellDP, Frayn KN. Prior shortterm consumption of resistant starch enhances postprandial insulin sensitivity in healthy subjects. Diabetologia. 2003; 46(5):659-65.

13. Edward Chambers NG, Alexander Viardot, Gar Frost. Dietary starch and fiber: potential benefits to body weight and glucose metabolism. Diabetes Manage. 2011; 1(5):1758-1907.

14. Delcour JA, Bruneel C, Derde LJ, Gomand SV, Pareyt B, Putseys JA, et al. Fate of starch in food processing: from raw materials to final food products. Annu Rev Food Sci Technol. 2010; 1:87-111. doi: 10.1146/annurev.food.102308.124211.

15. Bleich S, Cutler D, Murray C, Adams A. Why is the developed world obese? Annu Rev Public Health. 2008; 29:273-95. doi: 10.1146/ annurev.publhealth.29.020907.090954.

16. Englyst HN, Kingman SM, Cummings JH. Classification and measurement of nutritionally important starch fractions. Eur J Clin Nutr. 1992; 46(Suppl 2):S33-50.

17. Zhu F, Wang S, Wang YJ. Physical properties and enzyme susceptibility of rice and high-amylose maize starch mixtures. J Sci Food Agric. 2013. ; 93(12):3100-6. doi: 10.1002/jsfa.6146.

18. Backhed F, Ding H, Wang T, Hooper LV, Koh GY, Nagy A, et al. The gut microbiota as an environmental factor that regulates fat storage. Proc Natl Acad Sci USA. 2004; 101(44):15718-23.

19. DiBaise JK, Zhang H, Crowell MD, Krajmalnik-Brown R, Decker GA, Rittmann BE. Gut microbiota and its possible relationship with obesity. Mayo Clin Proc. 2008; 83(4):460-9. doi: 10.4065/83.4.460.

20. Qin J, Ruiqiang Li, Jeroen Raes, Manimozhiyan Arumugam, Kristoffer Solvsten Burgdorf, Chaysavanh Manichanh, et al. A human gut microbial gene catalogue established by metagenomic sequencing. Nature. 2010; 464(7285):59-65. doi: 10.1038/nature08821.

21. Walker AW, Ince J, Duncan SH, Webster LM, Holtrop G, Ze X, et al. Dominant and diet-responsive groups of bacteria within the human colonic microbiota. ISME J. 2011; 5(2):220-30. doi: 10.1038/ ismej.2010.118.
22. Ley RE, Peter J Turnbaugh, Samuel Klein, Jeffrey I Gordon. Microbial ecology: human gut microbes associated with obesity. Nature. 2006; 444(7122):1022-3. doi:10.1038/4441022a.

23. Tap J, Mondot S, Levenez F, Pelletier E, Caron C, Furet JP, et al. Towards the human intestinal microbiota phylogenetic core. Environ Microbiol. 2009; 11(10):2574-84. doi: 10.1111/j.14622920.2009.01982.x.

24. Abell GC, Cooke CM, Bennett CN, Conlon MA, McOrist AL. Phylotypes related to Ruminococcus bromii are abundant in the large bowel of humans and increase in response to a diet high in resistant starch. FEMS Microbiol Ecol. 2008; 66(3):505-15. doi: 10.1111/j.1574-6941.2008.00527.x.

25. Herbeck JL, Bryant MP. Nutritional features of the intestinal anaerobe Ruminococcus bromii. Appl Microbiol. 1974; 28(6):101822.

26. Leitch EC, Walker AW, Duncan SH, Holtrop G, Flint HJ. Selective colonization of insoluble substrates by human faecal bacteria. Environ Microbiol. 2007; 9(3):667-79.

27. Bouhnik $Y$, Raskine L, Simoneau G, Vicaut E, Neut C, Flourié B, et al. The capacity of nondigestible carbohydrates to stimulate fecal bifidobacteria in healthy humans: a double-blind, randomized, placebo-controlled, parallel-group, dose-response relation study. Am J Clin Nutr. 2004; 80(6):1658-64.

28. Ventura M, Turroni F, Lugli GA, van Sinderen D. Bifidobacteria and humans: our special friends, from ecological to genomics perspectives. J Sci Food Agric. 2014; 94(2):163-8. doi: 10.1002/ jsfa.6356.

29. Cummings JH, Macfarlane GT. The control and consequences of bacterial fermentation in the human colon. J Appl Bacteriol. 1991; 70(6):443-59.

30. Wang X, Brown IL, Khaled D, Mahoney MC, Evans AJ, Conway PL. Manipulation of colonic bacteria and volatile fatty acid production by dietary high amylose maize (amylomaize) starch granules. J Appl Microbiol. 2002; 93(3):390-7.

31. Noakes M, Clifton PM, Nestel PJ, Le Leu R, McIntosh G. Effect of high-amylose starch and oat bran on metabolic variables and bowel function in subjects with hypertriglyceridemia. Am J Clin Nutr. 1996; 64(6):944-51.

32. Nicholson JK, Holmes E, Kinross J, Burcelin R, Gibson G, Jia W, et al. Host-gut microbiota metabolic interactions. Science. 2012; 336(6086):1262-7. doi: 10.1126/science.1223813.

33. Samuel BS, Shaito A, Motoike T, Rey FE, Backhed F, Manchester JK, et al. Effects of the gut microbiota on host adiposity are modulated by the short-chain fatty-acid binding $\mathrm{G}$ protein-coupled receptor, Gpr41. Proc Natl Acad Sci USA. 2008; 105(43):16767-72. doi: 10.1073/pnas.0808567105.

34. Macfarlane S, Macfarlane GT. Regulation of short-chain fatty acid production. Proc Nutr Soc. 2003; 62(1):67-72.

35. Slavin JL. Position of the American Dietetic Association: health implications of dietary fiber. J Am Diet Assoc. 2008; 108(10):171631.

36. Akanji AO, Bruce MA, Frayn KN. Effect of acetate infusion on energy expenditure and substrate oxidation rates in non-diabetic and diabetic subjects. Eur J Clin Nutr. 1989; 43(2):107-15.

37. Akanji AO, Humphreys S, Thursfield V, Hockaday TD. The relationship of plasma acetate with glucose and other blood intermediary metabolites in non-diabetic and diabetic subjects. Clin Chim Acta. 1989; 185(1):25-34.

38. Suokas A, Kupari M, Heikkilä J, Lindros K, Ylikahri R. Acute cardiovascular and metabolic effects of acetate in men. Alcohol Clin Exp Res. 1988; 12(1):52-8. 
Citation: S Katherine Sweatt MAEd, Gordon Fisher PhD and Barbara A Gower PhD (2016) Effects of Resistant Starch Intake in Humans. F Nutr Reprt 1(2): 19-26. doi: https://doi.org/10.24218/fnr.2015.09.

39. Lupton JR. Microbial degradation products influence colon cancer risk: the butyrate controversy. J Nutr. 2004; 134(2):479-82.

40. Vieira EL, Leonel AJ, Sad AP, Beltrão NR, Costa TF, Ferreira TM, et al. Oral administration of sodium butyrate attenuates inflammation and mucosal lesion in experimental acute ulcerative colitis. J Nutr Biochem. 2012; 23(5):430-6. doi: 10.1016/j.jnutbio.2011.01.007.

41. Nagengast FM, Hectors MP, Buys WA, van Tongeren JH. Inhibition of secondary bile acid formation in the large intestine by lactulose in healthy subjects of two different age groups. Eur J Clin Invest. 1988; 18(1):56-61.

42. Heijnen ML, van Amelsvoort JM, Deurenberg P, Beynen AC. Limited effect of consumption of uncooked (RS2) or retrograded (RS3) resistant starch on putative risk factors for colon cancer in healthy men. Am J Clin Nutr. 1998; 67(2):322-31.

43. Lapre JA, Van der Meer R. Diet-induced increase of colonic bile acids stimulates lytic activity of fecal water and proliferation of colonic cells. Carcinogenesis. 1992; 13(1):41-4.

44. van Munster IP, Tangerman A, Nagengast FM. Effect of resistant starch on colonic fermentation, bile acid metabolism, and mucosal proliferation. Dig Dis Sci. 1994; 39(4):834-42.

45. Zhou J, Martin RJ, Tulley RT, Raggio AM, McCutcheon KL, Shen L, et al. Dietary resistant starch upregulates total GLP-1 and PYY in a sustained day-long manner through fermentation in rodents. Am J Physiol Endocrinol Metab. 2008; 295(5):E1160-6. doi: 10.1152/ ajpendo.90637.2008.

46. de Roos N, Heijnen ML, de Graaf C, Woestenenk G, Hobbel E. Resistant starch has little effect on appetite, food intake and insulin secretion of healthy young men. Eur J Clin Nutr. 1995; 49(7):532-41.

47. Bodinham CL, Frost GS, Robertson MD. Acute ingestion of resistant starch reduces food intake in healthy adults. Br J Nutr. 2010; 103(6):917-22. doi: 10.1017/S0007114509992534.

48. Karaki S, Tazoe H, Hayashi H, Kashiwabara H, Tooyama K, Suzuki Y,et al. Expression of the short-chain fatty acid receptor, GPR43, in the human colon. J Mol Histol. 2008; 39(2):135-42.

49. Adrian TE, Ferri GL, Bacarese-Hamilton AJ, Fuessl HS, Polak JM, Bloom SR. Human distribution and release of a putative new gut hormone, peptide YY. Gastroenterology. 1985; 89(5):1070-7.

50. Maki KC, Pelkman CL, Finocchiaro ET, Kelley KM, Lawless AL, Schild $\mathrm{AL}$, et al. Resistant starch from high-amylose maize increases insulin sensitivity in overweight and obese men. J Nutr. 2012; 142(4):71723. doi: 10.3945/jn.111.152975.

51. Robertson MD, Bickerton AS, Dennis AL, Vidal H, Frayn KN. Insulinsensitizing effects of dietary resistant starch and effects on skeletal muscle and adipose tissue metabolism. Am J Clin Nutr. 2005; 82(3):559-67.

52. Robertson MD, Wright JW, Loizon E, Debard C, Vidal H, ShojaeeMoradie $\mathrm{F}$, et al. Insulin-sensitizing effects on muscle and adipose tissue after dietary fiber intake in men and women with metabolic syndrome. J Clin Endocrinol Metab. 2012; 97(9):3326-32. doi: 10.1210/jc.2012-1513.

53. Tan GD, Debard C, Funahashi T, Humphreys SM, Matsuzawa Y, Frayn $\mathrm{KN}$, et al. Changes in adiponectin receptor expression in muscle and adipose tissue of type 2 diabetic patients during rosiglitazone therapy. Diabetologia. 2005; 48(8):1585-9.

54. Langin D, Dicker A, Tavernier G, Hoffstedt J, Mairal A, Rydén M, et al. Adipocyte lipases and defect of lipolysis in human obesity. Diabetes. 2005; 54(11):3190-7.

55. Ge H, Li X, Weiszmann J, Wang P, Baribault H, Chen JL, et al. Activation of $\mathrm{G}$ protein-coupled receptor 43 in adipocytes leads to inhibition of lipolysis and suppression of plasma free fatty acids. Endocrinology. 2008; 149(9):4519-26. doi: 10.1210/en.2008-0059.
56. Bloomer RJ, John F Trepanowski, Mohammad M Kabir, Rick J Alleman Jr, Michael E Dessoulavy . Impact of short-term dietary modification on postprandial oxidative stress. Nutr J. 2012; 11:16. doi: 10.1186/1475-2891-11-16.

57. Sies $\mathrm{H}$, Stahl W, Sevanian A. Nutritional, dietary and postprandial oxidative stress. J Nutr. 2005; 135(5):969-72.

58. Fisher-Wellman KH, Bloomer RJ. Exacerbated postprandial oxidative stress induced by the acute intake of a lipid meal compared to isoenergetically administered carbohydrate, protein, and mixed meals in young, healthy men. J Am Coll Nutr. 2010; 29(4):373-81.

59. Halcox JP, Donald AE, Ellins E, Witte DR, Shipley MJ, Brunner EJ, et al. Endothelial function predicts progression of carotid intimamedia thickness. Circulation. 2009; 119(7):1005-12. doi: 10.1161/ CIRCULATIONAHA.108.765701.

60. Jemal A, Siegel R, Xu J, Ward E. Cancer statistics, 2010. CA Cancer J Clin. 2010; 60(5):277-300. doi: 10.3322/caac.20073.

61. Hanahan D, Weinberg RA. Hallmarks of cancer: the next generation. Cell. 2011; 144(5):646-74. doi: 10.1016/j.cell.2011.02.013.

62. Scheppach W, Bingham S, Boutron-Ruault MC, Gerhardsson de Verdier M, Moreno V, Nagengast FM, et al. WHO consensus statement on the role of nutrition in colorectal cancer. Eur J Cancer Prev. 1999; 8(1):57-62.

63. Bartram HP, Scheppach W, Heid C, Fabian C, Kasper H. Effect of starch malabsorption on fecal bile acids and neutral sterols in humans: possible implications for colonic carcinogenesis. Cancer Res. 1991; 51(16):4238-42.

64. Hylla S, Gostner A, Dusel G, Anger H, Bartram HP, Christl SU, et al. Effects of resistant starch on the colon in healthy volunteers: possible implications for cancer prevention. Am J Clin Nutr. 1998; 67(1):136-42.

65. Wacker M, Wanek P, Eder E, Hylla S, Gostner A, Scheppach W. Effect of enzyme-resistant starch on formation of $1, N(2)$ propanodeoxyguanosine adducts of trans-4-hydroxy-2-nonenal and cell proliferation in the colonic mucosa of healthy volunteers. Cancer Epidemiol Biomarkers Prev. 2002; 11(9):915-20.

66. Burn J, Bishop DT, Mecklin JP, Macrae F, Möslein G, Olschwang S, et al. Effect of aspirin or resistant starch on colorectal neoplasia in the Lynch syndrome. N Engl J Med. 2008; 359(24):2567-78. doi: 10.1056/NEJMoa0801297.

67. Worthley DL, Le Leu RK, Whitehall VL, Conlon M, Christophersen C, Belobrajdic D, et al. A human, double-blind, placebocontrolled, crossover trial of prebiotic, probiotic, and synbiotic supplementation: effects on luminal, inflammatory, epigenetic, and epithelial biomarkers of colorectal cancer. Am J Clin Nutr. 2009; 90(3):578-86. doi: 10.3945/ajcn.2009.28106.

68. Dronamraju SS, Coxhead JM, Kelly SB, Burn J, Mathers JC. Cell kinetics and gene expression changes in colorectal cancer patients given resistant starch: a randomised controlled trial. Gut. 2009; 58(3):413-20. doi: 10.1136/gut.2008.162933.

69. van Gorkom BA, Karrenbeld A, van der Sluis T, Zwart N, van der Meer R, de Vries EG, et al. Calcium or resistant starch does not affect colonic epithelial cell proliferation throughout the colon in adenoma patients: a randomized controlled trial. Nutr Cancer. 2002; 43(1):31-8.

70. Grubben MJ, van den Braak CC, Essenberg M, Olthof M, Tangerman A, Katan MB, et al. Effect of resistant starch on potential biomarkers for colonic cancer risk in patients with colonic adenomas: a controlled trial. Dig Dis Sci. 2001; 46(4):750-6.

71. Malcomson FC, Willis ND, Mathers JC. Is resistant starch protective against colorectal cancer via modulation of the WNT signalling pathway? Proc Nutr Soc. 2015:1-10. doi: 10.1017/ S002966511500004X. 
Citation: S Katherine Sweatt MAEd, Gordon Fisher PhD and Barbara A Gower PhD (2016) Effects of Resistant Starch Intake in Humans. F Nutr Reprt 1(2): 19-26. doi: https://doi.org/10.24218/fnr.2015.09.

72. Scheppach W, Bartram HP, Richter F. Role of short-chain fatty acids in the prevention of colorectal cancer. Eur J Cancer. 1995; 31A(78):1077-80.

73. Strober W, Fuss I, Mannon P. The fundamental basis of inflammatory bowel disease. J Clin Invest. 2007; 117(3):514-21. doi: 10.1172/ JCl30587.

74. Roberfroid M. Prebiotics: the concept revisited. J Nutr. 2007; 137(3 Suppl 2):830S-7S.

75. Young GP. Colorectal disorders: A dietary management perspective. Asia Pac J Clin Nutr. 2000; 9(Suppl 1):S76-82.

76. Higgins JA. Resistant starch: metabolic effects and potential health benefits. J AOAC Int. 2004; 87(3):761-8.

77. Whitehead RH, Young GP, Bhathal PS. Effects of short chain fatty acids on a new human colon carcinoma cell line (LIM1215). Gut. 1986; 27(12):1457-63.

78. Heerdt BG, Houston MA, Augenlicht LH. Short-chain fatty acidinitiated cell cycle arrest and apoptosis of colonic epithelial cells is linked to mitochondrial function. Cell Growth Differ. 1997; 8(5):523-32.

79. Andoh A, Tsujikawa T, Fujiyama Y. Role of dietary fiber and shortchain fatty acids in the colon. Curr Pharm Des. 2003; 9(4):347-58.

80. Bern C, Martines J, de Zoysa I, Glass RI. The magnitude of the global problem of diarrhoeal disease: a ten-year update. Bull World Health Organ. 1992; 70(6):705-14.
81. Ramakrishna BS, Roediger WE. Bacterial short chain fatty acids: their role in gastrointestinal disease. Dig Dis. 1990; 8(6):337-45.

82. Ruppin H, Bar-Meir S, Soergel KH, Wood CM, Schmitt MG Jr. Absorption of short-chain fatty acids by the colon. Gastroenterology. 1980; 78(6):1500-7.

83. Binder HJ. Role of colonic short-chain fatty acid transport in diarrhea. Annu Rev Physiol. 2010; 72:297-313. doi: 10.1146/ annurev-physiol-021909-135817.

84. Binder HJ, Mehta P. Short-chain fatty acids stimulate active sodium and chloride absorption in vitro in the rat distal colon. Gastroenterology. 1989; 96(4):989-96.

85. Krishnan S, Rajan DP, Ramakrishna BS. The ability of enteric diarrhoeal pathogens to ferment starch to short-chain fatty acids in vitro. Scand J Gastroenterol. 1998; 33(3):242-6.

86. Gancz H, Niderman-Meyer O, Broza M, Kashi Y, Shimoni E. Adhesion of Vibrio cholerae to granular starches. Appl Environ Microbiol. $2005 ; 71(8): 4850-5$.

87. Kaper JB, Morris Jr JG, Levine MM. Cholera. Clin Microbiol Rev. 1995; 8(1):48-86.

88. Bird AR, Brown IL, Topping DL. Starches, resistant starches, the gut microflora and human health. Curr Issues Intest Microbiol. 2000; 1(1):25-37. 